\title{
Passive transfer of learned
}

\section{dark and step-down avoidance}

\author{
HELENE N. GUTTMAN and LISA GRONKE \\ Department of Biological Sciences \\ University of Illinois at Chicago Circle, Chicago, Ill. 60680
}

Passive chemical transfer of two specific learned tasks, (1) dark avoidance and (2) step-down avoidance, was demonstrated by IP injection into mice of purified $R N A$-free peptides isolated from rat brains. The dark avoidance work confirms earlier work by Ungar. Step-down avoidance is passively transferred by a small peptide, for which the name catabathmophobin is suggested. Specific methods for the isolation of behavior-altering peptides are described, and the present status of passive-transfer studies is briefly discussed.

Although a chemical mode for long-term storage of learned behavior was suggested more than 20 years ago (Katz \& Halstead, 1950), experimental test of the idea waited another decade. The choice of animals, every stage of the test situation (from paradigm to molecular isolation procedures), and subsequent results have aroused so much argument that recent striking progress made in a few laboratories has been for the most part obscured. In the light of the report by Ungar's group 1 that a 15-amino-acid brain peptide responsible for passive transfer of dark avoidance had been isolated and its structure proved by synthesis of a completely active duplicate, we feel it important to present independent confirmation of the dark-avoidance studies. Using the same general experimental methods, these studies have been extended to another paradigm, step-down avoidance, for which a molecule with similar (but not identical) properties has been isolated and partly characterized.

SUBJECTS

Male albino rats were used as donors, and male albino mice were used as recipients. Since there was considerable difference in dark (over light) preference time among rats supplied from different vendors, only rats from Holtzman Co., Madison, Wisconsin, were used, since these rats spent at least $75 \%$ of each 180 -sec dark-light choice trial in the dark. There was only trivial variation in step-down time among rats from different vendors.

\section{APPARATUS}

The dark-avoidance box was identical to that used by Ungar $(1970 \mathrm{~b})$ and was fabricated by the same craftsman in the Baylor Medical School shop. The step-down box was $33 \times 38 \times 33 \mathrm{~cm}$ (L/W/D), and its floor was overlaid with an electrifiable grid composed of copper alloy rods at $1-\mathrm{cm}$ intervals. The $11.5 \times 7.5 \mathrm{~cm}$ platform was set into the $33-\mathrm{cm}$ wall, $12.5 \mathrm{~cm}$ above the grid. A clear plastic lid was placed over the box during use.

\section{BEHAVIORAL PROCEDURES}

A minimum of 1 week intervened between arrival of animals and experimental use. During that period, they were handled individually daily and were housed one/cage for rats or several/cage for mice. Failure to observe these gentling procedures causes extreme experimental variability. After the gentling period, rats were used as controls or experimentals in (1) dark-avoidance experiments if they spent $23 / 180 \pm 18 \mathrm{sec}$ in the light in eight screening trials, (2) step-down avoidance experiments if their step-down time in 10 sequential trials (with 60-sec intertest interval, ITI) averaged 2.2-3.3 sec. Recipient mice were screened according to similar criteria.

\section{Donor Training}

Dark avoidance. Both experimental and control donors were given five consecutive trials with 30-sec ITI for 7 consecutive days. Control donors received neither punishment nor reward: the time (out of $180 \mathrm{sec}$ ) spent in the dark or light box was merely recorded. Experimental rats were closed into the dark box after they entered for the first time, given a 5-sec shock, and removed from the dark box. In subsequent trials, if the animal did not voluntarily enter the dark box, it was pushed in and treated as during the initial trial. Animals were sacrificed $2 \mathrm{~h}$ after the last training session by decapitation.

Step-down avoidance. Both experimental and control donors were carefully placed on the platform with their heads facing the side wall for 10 sequential trials (60-sec ITI). At the next trial, animals were divided into experimental or control groups or discarded if they did not meet criteria indicated under BEHAVIORAL PROCEDURES. Animals proved to be consistently usable: discards appeared necessary only when animal trainers lacked experience in animal handling.
The 11-14 trials for control animals were identical to the first 10 , but experimental animals were given a 5 -sec shock as soon as they stepped off the platform on the 11 th trial and immediately removed from the training box. If the experimental animal stayed on the platform for $180 \mathrm{sec}$ during the 12 th trial, it received no further trials. If it did not stay on the platform for $180 \mathrm{sec}$, it received a 5 -sec shock and was tested again $60 \mathrm{sec}$ later. Booster training at $4 \mathrm{~h}$ was necessary only when new animal trainers were used, clearly an indication that a major cause of variability in experiments of this sort stems from the $E$. All experimental animals were tested for retention $24 \mathrm{~h}$ after their last training session and sacrificed by decapitation on the 25 th retention hour. Controls were sacrificed at the same time.

Chemical Processing of Brains

For both experiments, brains were removed within $30 \mathrm{sec}$ of decapitation, frozen in liquid nitrogen, and stored at $-20^{\circ} \mathrm{C}$ until further processing. In both cases, extraction of the active behavioral principle followed methods outlined by Ungar $(1970 a, b)$. Since the protocol has never been published fully, we outline it here.

Frozen brains are partly thawed by placing them on crushed ice covered with mylar film (further steps are done at $4^{\circ} \mathrm{C}$ ) and homogenized in a blendor with $25 \%(\mathrm{w} / \mathrm{v})$ phenol containing $0.05 \mathrm{mM}$ EDTA. The homogenate is stirred for $20 \mathrm{~min}$ and then centrifuged at $2,000 \times \mathrm{g}$ for $10 \mathrm{~min}$. All of the aqueous phase is removed, recentrifuged at $25,000 \mathrm{x}$ g for $20 \mathrm{~min}$ and only the supernatant saved. The supernatant is adjusted to pH 5.5, $1.2 \mathrm{vol}$ isopropanol added, the mixture held in an ice bath for $20 \mathrm{~min}$, and then centrifuged at $2,000 \times \mathrm{g}$ for $15 \mathrm{~min}$. The pellet only is saved, redissolved in a minimum $0.1 \mathrm{mM}$ EDTA stirred for $2 \mathrm{~h}$ and centrifuged at $25,000 \times \mathrm{g}$ for $20 \mathrm{~min}$. In the key step which follows, the supernatant only is saved, its $\mathrm{pH}$ reduced to 4 to dissociate small peptides and other molecules from the major RNA fraction and the small molecules separated from the nondialyzable RNA by dialysis against $20 \mathrm{vol}$ of distilled water for $24 \mathrm{~h}$. The dialysate is lyophilized and for dark avoidance: redissolved in minimum water, eluted through a $2.5 \times 45 \mathrm{~cm}$ Sephadex G-25 column with pyridine:acetic acid:water $\quad(100: 4: 2400 \mathrm{v} / \mathrm{v} / \mathrm{v})$, fractions pooled, lyophilized, redissolved in $0.9 \%(\mathrm{w} / \mathrm{v})$ saline so that $0.3 \mathrm{ml}$ contained just under two rat equivalents of material, and refrigerated until use; for step-down avoidance: the Sephadex step was omitted. 


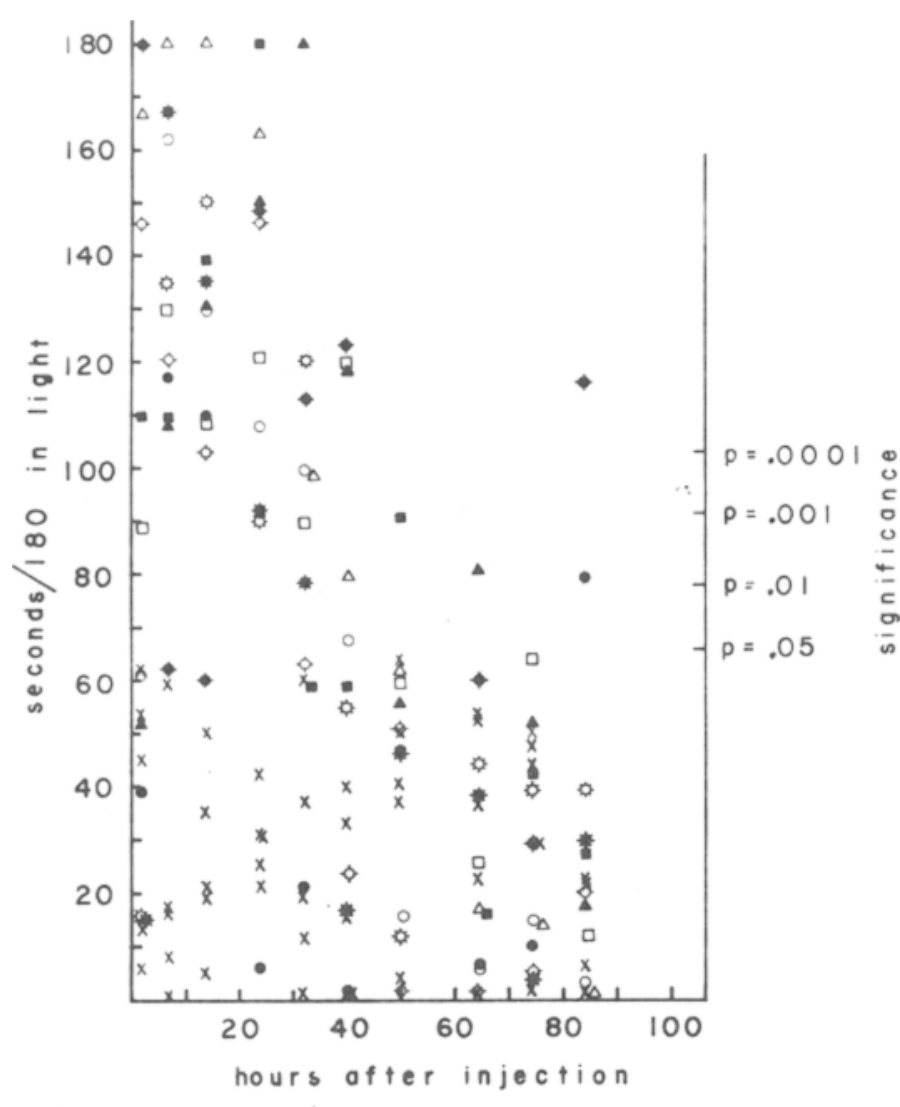

Fig. 1. Effect of ca 1,600 MW (scotophobin-rich) peptides from dark avoidance trained and untrained rats on dark avoidance in mice. Significance of differences in dark a voidance between individual mice which received scotophobin-rich rather than control peptides (calculated by Student's $t$ test) is indicated by the scale along the right-hand ordinate. Individual mice in the scotophobin-rich group are indicated by separate symbols so that variability among recipients can be followed. All controls are indicated by $\mathrm{X}$.

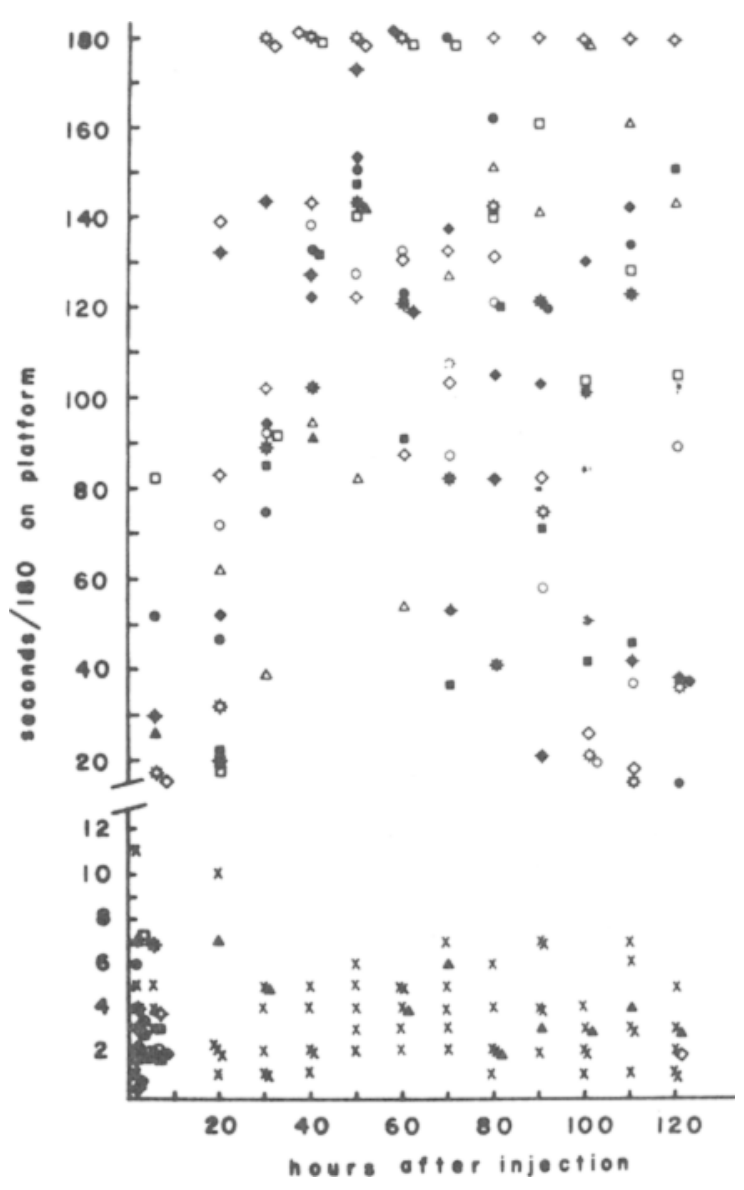

Fig. 2. Effect of small-peptide-rich dialysates from trained and untrained rats on step-down avoidance in mice. Individual mice in the catabathmophobin-rich group are indicated by separate symbols so that variability among recipients can be followed. All controls are indicated by $X$.
Treatment and

Testing Recipients

In all cases, recipient mice received $0.3 \mathrm{ml}$ purified brain fraction IP and were tested, without reinforcement in the same boxes used to train donors. Recipients were coded so that the tester was unaware of the nature of their injection.

\section{RESULTS}

Dark Avoidance

The elution patterns (absorbance $280 \mathrm{~nm}$ ) of experimental and control preparations through Sephadex columns confirmed (Ungar, personal communcation) the presence of several molecules in the $1,000-2,000 \mathrm{MW}$ range which had at least one aromatic residue and the low degree of aromaticity in the fractions containing MW 1,600 material. Since Ungar et al (1971) reported that the step-down avoidance principle, therein named scotophobin, has a molecule weight of 1,600 and has only one aromatic residue, we pooled the column eluates which bracketed this range and tested both this putatively active material and a slightly larger fraction of control eluate. As can be seen (Fig. 1), mice which received the control material consistently spent $2-64 / 180$ sec in the light, while mice which received experimental material began to show differences during the first test period, $2 \mathrm{~h}$ after injection. Variability of response among animals can be seen by following the responses of individual animals. The periods during which individual experimental animals differed significantly from the controls are easily marked by comparison with the significance scale (Fig. 1). Step-down Avoidance

Mice which received the control preparation (Fig. 2) behaved so uniformly that mice which remained on the platform for more than $15 / 180$ sec were clearly different from the controls. As can be seen, no mice which received control extracts remained on the platform more than $11 \mathrm{sec}$, and all mice which received experimental extracts were positive for step-down avoidance. Variability of response related to onset, duration, and magnitude of the step-down avoidance response resembles that noted for dark avoidance. Although it is fairly clear that this variability is due to some property of the recipients, analysis of preinjection screening performance of recipients failed to reveal any clues.

\section{DISCUSSION}

Our finding, that a non-RNA molecule of molecular weight ca 1,500 from rat brain can passively transfer dark avoidance to mice, clearly confirms the reports of Ungar $(1970 a, b)$ and gives us reason to expect that completion of the purification process would show identity of our active principle with the 15 amino acid peptide, scotophobin, which Ungar et al (1971) have identified and whose activity has 
been confirmed by synthesis. Since both our unpublished studies and Ungar (1970a) showed, with crude preparations, that there is no crossover effect between dark and step-down avoidance, an effect due to the conditioning stimulus is ruled out and specificity of the active molecule is clearly seen. Further distinction between the two molecules is emphasized by the sensitivity of scotophobin to trypsin, but not to chymotrypsin (Ungar, 1970b), and the sensitivity of crude preparations of step-down avoidance principle to both proteolytic enzymes. We propose the name "catabathmophobin" for the active step-down avoidance principle (from the Greek kata = down, bathmos = step, and phobos = fear).

It is, therefore, becoming increasingly clear that there is a family of relatively small peptides, in the $\mathrm{MW}$ 1,500 range, which are active in passive transfer of rather simple behavioral responses. Our current work, aimed at the complete structural identification of the step-down avoidance peptide, should help determine the general structural qualifications for transfer activity as well as for specificity in much the same way that immunoglobulins are now known to require a general structure which allows reaction with antibody as well as specific amino acid sequences in the variable portion of the immunoglobulin which controls specificity of the response.

An analogy also exists between the present status of our knowledge of the molecular identification of the first passive transfer molecule, scotophobin, and the state of enzymology in 1926, when Sumner crystallized the first enzyme, urease, and showed that it was a protein. Enzymologists of the 1930 s argued furiously about whether or not enzymes were proteins, and some were not convinced until several other enzymes were crystallized and shown to be proteins. An added problem in the clarification of passive transfer of learned behavior which did not exist in early enzymology is that behaviorai and biochemical conditions required for even the demonstration of passive transfer of learned behavior are so poorly known that we have almost simultaneous reports of failure to demonstrate any passive transfer (Lepore et al, 1970) from one laboratory and structural resolution of passive transfer molecule from another (Ungar et al, 1971).

REFERENCES

BYRNF, W. L. (Ed.) Mntrewtar approaches to tcoming and memory. New Yurk: Academic Press, 1970.
KATZ,M.S.\& HALSTEAD, W. C. Protein organiration and mental function. Comparative Psychology Monograph. $1950,20(1), 1-38$

LEPORE, F. DUCHARME, R., \& CARDU. B. Memory and ribonucleic acid (RNA): Transfer of an avoidance responst. Psychological Reports, 1970,27,99-103. UNGAR. G. (Ed.) Molecular mechanisms in memory and learning. New York: PJenum, 1970a. Pp. 149-175.
UNGAR, G. C'bemical tranifor of leamed information. in W. [. Byrne (Ed.). Molecular approache's (o learning and memory. New York: Academic Press, 1970b. Pp. 179-187.

NOTE

1. Ungar. G., Desiderio. D. M., and Parr, W. Isolation, identification and synthesis of a specific-behavior-inducing brain peptide. Submitted for publication.

\title{
The incubation effect produced in rats without footshock*
}

\author{
JOHN P. J. PINEL† \\ University of British Columbia, Vancouver, Canada \\ and \\ CHARLES W. MALSBURY and MICHAEL EDWARD CORCORAN \\ McGill University, Montreal, Canada
}

A noncontingent aversive treatment consisting of high-intensity sound and air blast was administered to rats in an open field. These animals were returned to the open field $30 \mathrm{sec}, 1 \mathrm{~min}, 10 \mathrm{~min}, 1 \mathrm{~h}, 3 \mathrm{~h}$, or $8 \mathrm{~h}$ later, and their activity levels were recorded. The aversive treatment significantly reduced activity from pretreatment levels. The magnitude of this reduction increased with increases in the treatment-test interval. Thus, it was clearly shown that the "incubation effect" is not peculiar to situations in which footshock serves as the noxious stimulus.

After a noncontingent footshock (FS) administered in an open field, the freezing behavior observed during reexposure to that open field increases with increases in the duration of the FS test interval (Pinel, 1970). In a recent paper, Pinel, Corcoran, and Malsbury ${ }^{1}$ showed that this increase in freezing after FS is not attributable to an increase in the tendency to freeze, but rather is related to the transient activating effects of FS. Animals tested soon after FS were relatively active, not because there was little tendency to freeze at that time, but because the freezing effects were being partially counteracted by FS-produced activation. The increases in freezing seen with increases in the duration of the FS test interval reflected a diminution of these activating effects. Thus, it appears that the failure to freeze in the intervals after FS was not merely a passive deficit due to the slowness of mechanisms underlying the development of FS-produced freezing. There seem to be mechanisms which actively delayed the onset of

* Supported by Canadian National Research Council Grant APA-66 awarded to $P$. M. Milner. The senior author was supported during preparation of the manuscript by National Institute of Mental Health Grant 5-R01-MH07923 awarded to S. L. Chorover.

tRequests for reprints should be sent to John Pine?. who is now at the Department of Psychology. University of Britisti Columbia, Vancouver 8 , Canada. freezing and thus ensured that animals remained active in the immediate post-FS period.

These mechanisms seem to underlie a number of different phenomena which all have been included under the label of "incubation effect." In the one-trial passive avoidance and conditioned emotional-response situations, where increases in freezing can result in improved performance, performance has been shown to improve with increases in the duration of the FS test interval (McGaugh, 1966; Pinel \& Cooper, 1966; Tarpy, 1966). On the other hand, in the one-trial active avoidance situation, increases in freezing disrupt avoidance and performance has been found to deteriorate as the duration of the FS test interval increases (Pinel, 1968).

Numerous investigators have demonstrated the incubation effect in a wide variety of species and under a wide variety of conditions (e.g., Bovet, Filomena, \& Alberto, 1969; McMichael, 1966; Zammit-Montebello, Black, Marquis, \& Suboski, 1969). This suggests that the incubation effect might reflect a natural behavior pattern which may have survival value for a number of different species. This conjecture, however, remains in doubt because FS has been used as the aversive stimulus in all demonstrations of the incubation ef fect. On the basis of existing data, it is hard to rule out the possibility that the incubation effect 